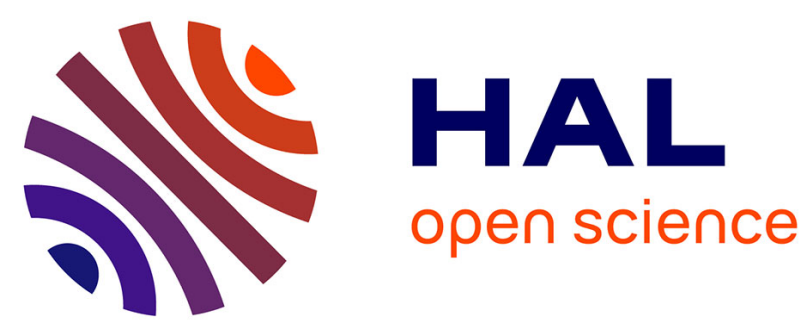

\title{
Description of musculoskeletal disorders and occupational exposure from a field pilot study of large population-based cohort (CONSTANCES)
}

Matthieu Carton, Annette Leclerc, Sandrine Plouvier, Eléonore Herquelot, Marie Zins, Marcel Goldberg, Yves Roquelaure, Alexis Descatha

\section{To cite this version:}

Matthieu Carton, Annette Leclerc, Sandrine Plouvier, Eléonore Herquelot, Marie Zins, et al.. Description of musculoskeletal disorders and occupational exposure from a field pilot study of large population-based cohort (CONSTANCES). Journal of Occupational and Environmental Medicine, 2013, 55, pp.859-61. 10.1097/JOM.0b013e31825fa545 . hal-03391058

\section{HAL Id: hal-03391058 \\ https://univ-angers.hal.science/hal-03391058}

Submitted on 21 Oct 2021

HAL is a multi-disciplinary open access archive for the deposit and dissemination of scientific research documents, whether they are published or not. The documents may come from teaching and research institutions in France or abroad, or from public or private research centers.
L'archive ouverte pluridisciplinaire HAL, est destinée au dépôt et à la diffusion de documents scientifiques de niveau recherche, publiés ou non, émanant des établissements d'enseignement et de recherche français ou étrangers, des laboratoires publics ou privés. 
Readers are invited to submit letters for publication in this department. Submit letters online at http://joem.edmgr.com. Choose "Submit New Manuscript." A signed copyright assignment and financial disclosure form must be submitted with the letter. Form available at www.joem.org under Author and Reviewer information.

\section{Description of Musculoskeletal Disorders and Occupational Exposure From a Field Pilot Study of Large Population-Based Cohort (CONSTANCES)}

\section{$\mathrm{M}$}

To the Editor usculoskeletal disorders (MSDs) have become one of the most significant and costly health problems in the working population. Information about the prevalence of MSDs available in the literature, mainly coming from specific companybased studies, may suffer from a lack of comparability because of the variability of the population. ${ }^{1-4}$ Because the relative importance of each risk factor for MSDs varies according to work environments, ${ }^{5}$ these studies should be extrapolated to the entire working population with caution. ${ }^{6}$ Furthermore, besides the occupational setting potentially leading to overrating or underrating of MSD or exposure, depending on the potential benefit or risk to social status of the workers, these studies have problems in observing workers, especially those with temporary jobs.

The "Cohorte des consultants des Centres d'examens de santé" (CONSTANCES) project was designed to set up a large population-based longitudinal cohort designed as an "open epidemiologic laboratory" accessible to the epidemiologic research community with the aim of contributing to the development of epidemiologic research and to provide useful public health information. In conclusion, the cohort was composed of a random sample of adults aged 18 to 69 years at inception, and inclusion took place in Health Screening Centers (HSCs). ${ }^{7}$ We hypothesize that the information provided by cohort participants that will be included in HSCs will also provide information about participants usually

\footnotetext{
The authors declare that there are no conflicts of interest. The authors alone are responsible for the content and writing of the article.

Copyright (C) 2013 by American College of Occupational and Environmental Medicine

DOI: 10.1097/JOM.0b013e31825fa545
}

not observed in studies about occupational settings, such as unemployed population or temporary workers.

We made use of the data collected during the pilot phase of the project to describe the prevalence of MSDs and exposure to the risk factors. In view of setting up of the full CONSTANCES cohort, we checked whether their prevalence is similar to that in other large MSD studies. We also detailed the main characteristics of the participants, their exposure, and complaints to verify that HSCs and CONSTANCES could provide an interesting setting for studies about temporary workers and the unemployed population.

The study sample was taken from the field pilot study of CONSTANCES. It took place in seven of the participating HSCs throughout France, from May 2009 to May 2010 for a 4 - to 5-month period in each center. It was designed to include 3500 participants (women and men in almost equal numbers), and the preliminary analysis of the data showed that this sample was close to the general adult population in France regarding sex, age, and socioeconomic status. ${ }^{7}$ Most of the variables used in the field pilot study were taken from self-administered questionnaires. In the present study, we used the following: sociodemographic characteristics (sex, age, social position, educational and income levels, and employment status); and occupational factors (current occupational exposure to biomechanical hazards) that were collected based on the Saltsa consensus and the French MSD surveillance system. ${ }^{8,9}$ Specific scales for MSD based on the Nordic questionnaire were filled out. . $^{2,10,11}$ Presence of symptoms lasting at least 30 days during the past 12 months by site was also considered.

For unemployed population, only not retired participants and those with previous jobs were considered and compared with the working sample. In the working population, associations between type of contract and social position with sociodemographic characteristics, work exposure, and MSDs were described.

The sample included 3471 participants; 1643 men and 1829 women. Among them, 113 (3.2\%) never worked, $443(1.7 \%)$ reported to be retired, $328(9.4 \%)$ had no job, and $2587(74.5 \%)$ were working at the time of the study. The 328 participants (112 men and 216 women) who reported to be unemployed (not retired, but had never worked) were older (50 to 60 years) (men: $38.4 \%$ vs $26.7 \%$; women: $32.4 \%$ vs $25.4 \%$; $P<0.05)$ and more often blue-collar work- ers (men: $31.1 \%$ vs $22.2 \%$; women: $8.3 \%$ vs $4.8 \%$, respectively) compared with the working population. Unemployed men had significantly more shoulder persistent pain than working men $(22.6 \%$ vs $12.3 \%)$ and unemployed women had more hand, elbow, back, and knee pain $(22.3 \%, 13.6 \%, 36.1 \%$, and $26.0 \%$ vs $15.0 \%, 8.8 \%, 25.9 \%$, and $18.8 \%$, respectively) than working women. When the information was collected $(n=$ 180), unemployed people reported to be seeking a job $(53.9 \%, n=97)$, have voluntarily resigned from their jobs $(26.7 \%$, $n=48)$, or have a health problem $(19.4 \%$, $n=35$ )

Table 1 shows the prevalence of occupational exposure and persistent musculoskeletal pain in men and women according to social position and employment status. In men and women, there was a clear gradient between social position and prevalence of occupational exposure to physical effort, squatting position, working with arms up, or screwing with hand. In men, the prevalence of persistent back and knee pain increased with social position (not significant for other sites). In women, there is a clear gradient in the prevalence of pain with the social position for all sites except the neck. Very few women reported temporary jobs. In men and women, occupational exposures were strongly associated with employment status. Although very few men reported temporary jobs, they seemed to report more persistent musculoskeletal pain (significant only for elbows).

Finally, we considered whether the field pilot study gave a fair description of MSDs and biomechanical exposure in a large sample of the general population. Limitations came from the design of the pilot study and its inclusion criteria. The study had a cross-sectional design based on a large and nontargeted population. Nevertheless, we found the globally expected levels of exposure and pain. The first results regarding temporary workers and unemployed populations clearly open a way for more research on these usually hard-to-reach populations in occupational studies. ${ }^{12-15}$ The high prevalence of MSDs in our sample of temporary workers and participants who had to stop working is promising for future research within the large longitudinal CONSTANCES cohort.

\section{CONCLUSIONS}

This field pilot study showed valid results about MSDs with interesting information for particular populations of usually 


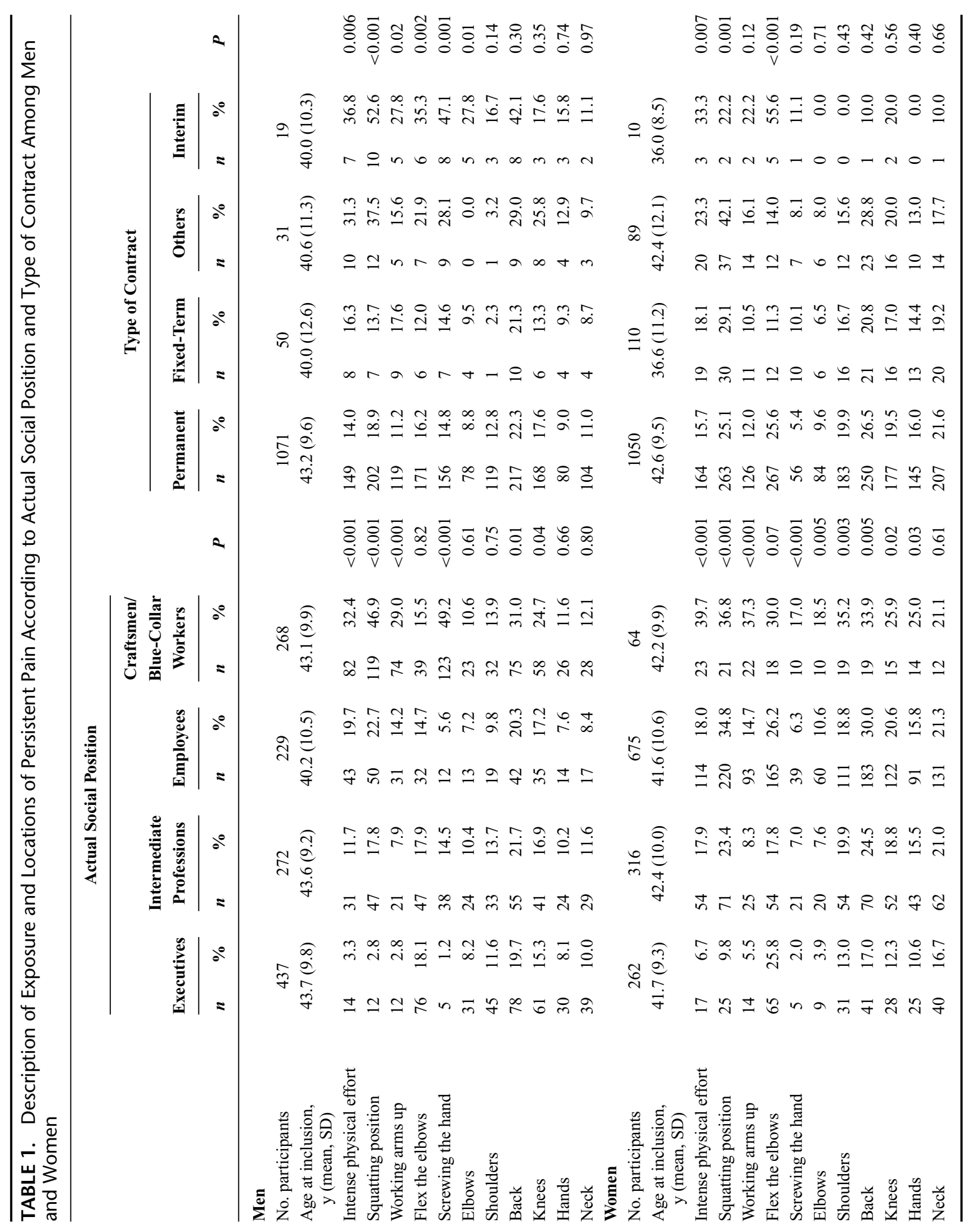


unreached participants. The limited sample will be extended and would give additional material for studying these populations.

\section{Matthieu Carton, MD Annette Leclerc, PhD \\ Sandrine Plouvier, MD, PhD Eleonore Herquelot, MSc Marie Zins, MD \\ Marcel Goldberg, MD, PhD \\ "Population-Based Epidemiological \\ Cohorts" Research Platform \\ Centre for Research in Epidemiology and Population Health \\ Université de Versailles Saint Quentin-Inserm Villejuif, France \\ Yves Roquelaure, MD, PhD \\ "Population-Based Epidemiological \\ Cohorts" Research Platform \\ Centre for Research in Epidemiology and Population Health \\ Université de Versailles Saint Quentin-Inserm Villejuif, France \\ Laboratoire d'Ergonomie et d'Epidémiologie en Santé au Travail LUNAM, Université d'Angers CHU Angers, France \\ Alexis Descatha, MD "Population-Based Epidemiological Cohorts" Research Platform \\ Centre for Research in Epidemiology and Population Health \\ Université de Versailles Saint Quentin-Inserm Villejuif, France AP-HP Occupational Health Department University Hospital of Paris West Suburb, Poincaré site CHU Garches, France \\ REFERENCES \\ 1. Silverstein BA, Stetson DS, Keyserling WM, Fine LJ. Work-related musculoskeletal disor- ders: comparison of data sources for surveil- lance. Am J Ind Med. 1997;31:600-608. \\ 2. Descatha A, Roquelaure Y, Chastang JF, et al. Validity of Nordic-style questionnaires in the surveillance of upper-limb work-related mus- culoskeletal disorders. Scand J Work Environ Health. 2007;33:58-65. \\ 3. Palmer KT, Reading I, Calnan M, Coggon D. How common is repetitive strain injury? Occup on differences in the determinants of a specific shoulder disorder versus nonspecific shoulder pain without clinical findings. Am J Epidemiol. 2005; 161:847-855. \\ 7. Zins M, Bonenfant S, Carton M, et al. The CON- STANCES cohort: an open epidemiological lab- oratory. BMC Public Health. 2010;10:479. \\ 8. Sluiter BJ, Rest KM, Frings-Dresen MH. Crite- ria document for evaluating the work-relatedness of upper-extremity musculoskeletal disorders. Scand J Work Environ Health. 2001;27(suppl 1):1-102. \\ 9. Roquelaure Y, Ha C, Leclerc A, et al. Epidemi- ologic surveillance of upper-extremity muscu- loskeletal disorders in the working population. Arthritis Rheum. 2006;55:765-778. \\ 10. Kuorinka I, Jonsson B, Kilbom A, et al. Stan- dardised Nordic questionnaires for the analy- sis of musculoskeletal symptoms. Appl Ergon. 1987; 18:233-237. \\ 11. Palmer K, Smith G, Kellingray S, Cooper C. Repeatability and validity of an upper limb and neck discomfort questionnaire: the utility of the standardized Nordic questionnaire. Occup $\mathrm{Med}$ (Lond). 1999;49:171-175. \\ 12. Virtanen M, Kivimäki M, Joensuu M, et al. Tem- porary employment and health: a review. Int $J$ Epidemiol. 2005;34:610-622. \\ 13. Benach J, Amable M, Muntaner C, Benavides FG. The consequences of flexible work for health: are we looking at the right place? $J$ Epidemiol Community Health. 2002;56:405- 406. \\ 14. Smith CK, Silverstein BA, Bonauto DK, Adams $\mathrm{D}$, Fan ZJ. Temporary workers in Washington State. Am J Ind Med. 2010;53:135-145. \\ 15. Roquelaure Y, Petit Lemanach $\mathrm{A}, \mathrm{Ha} \mathrm{C}$, et al. Working in temporary employment and expo- sure to musculoskeletal constraints. Occup Med (Lond). 2012 February 17 [epub ahead of print]. \\ Safe Lifting and Apparently Conflicting Evidence: Increase Understanding for Making Progress in Prevention of Musculoskeletal Disorders} Environ Med. 2008;65:331-335.

4. Bonneterre V, Faisandier L, Bicout D, et al. Programmed health surveillance and detection of emerging diseases in occupational health: contribution of the French national occupational disease surveillance and prevention network (RNV3P). Occup Environ Med. 2010;67:178186.

5. Bernard BP. Musculoskeletal Disorders and Workplace Factors: A Critical Review of Epidemiologic Evidence for Work-Related Musculoskeletal Disorders of the Neck, the UpperLimb, and Low Back. Cincinnati, OH: Centers for Disease Control and Prevention, NIOSH; 1997.

6. Miranda H, Viikari-Juntura E, Heistaro S, Heliovaara M, Riihimaki H. A population study

\section{To the Editor:}

М e would like to compliment $\sqrt{\text { Restrepo }^{1}}$ and Gucer $^{2}$ and their colleagues on taking up the challenge of evaluating the use of safe lifting practices,

The authors declare no conflicts of interest.

Copyright (C) 2013 by American College of Occupational and Environmental Medicine

DOI: 10.1097/JOM.0b013e3182882c5b including the use of mechanical lifts both from the perspective of the caregivers and the residents. This is of major importance because we seem to make slow progress in preventing musculoskeletal disorders in health care staff and that is not for a want of trying. ${ }^{3}$ One important reason for this slow progress might be that we rely too much on the implementation of seemingly effective interventions. Both authors state firmly in their articles that evidence is available that the use of powered mechanical lifts prevent the onset of work-related musculoskeletal disorders or in their own words, "Several intervention studies have since shown that using mechanical lifts to assist frail patients clearly decreased worker injury from MSDs [musculoskeletal disorders]"1 and "Evidence linking the use of powered mechanical lifting in LTC [long-term care] facilities to reduced caregiver injuries has been accumulating," ${ }^{2}$ referring to primary scientific articles and general reports. In contrast to this statement about effectiveness, a Cochrane Review article that was recently updated concluded that manual material handling advice and training with or without assistive devices does not prevent back pain or back pain-related disability when compared with no intervention or alternative interventions. ${ }^{4,5}$ There is neither evidence available from randomized controlled trials nor controlled prospective studies for the effectiveness of manual material handling advice and training or manual material handling assistive devices for treating back pain. Remarkably, this review is not discussed nor referenced in the two articles. ${ }^{1,2}$ Given this apparently conflicting evidence, we would like to invite both authors to address why, in their opinion, the present intervention of safe lifting practices, including the use of mechanical lifts, differs from the interventions discussed in the Cochrane Review. In this way, we can learn and increase our understanding of why some interventions work and others do not.

P. Paul F.M. Kuijer, PhD

Coronel Institute of Occupational Health, Netherlands Center for Occupational Diseases, Academic Medical Center, University of Amsterdam, Amsterdam, the Netherlands

Jos H. Verbeek, MD, PhD Finnish Institute of Occupational Health, Kuopio, Finland

\section{REFERENCES}

1. Restrepo TE, Schmid FA, Gucer PW, Shuford HL, Shyong CJ, McDiarmid MA. Safe lifting programs at long-term care facilities and their impact on workers' compensation costs. J Occup Environ Med. 2013;55:27-35. 
2. Gucer PW, Gaitens J, Oliver M, McDiarmid MA Sit-stand powered mechanical lifts in long-term care and resident quality indicators. J Occup Environ Med. 2013;55:36-44.

3. Wells R. Sounding board: why have we not solved the MSD problem? Work. 2009;34:117-121.

4. Verbeek JH, Martimo KP, Karppinen J, Kuijer PP, Viikari-Juntura E, Takala EP. Manual material handling advice and assistive devices for preventing and treating back pain in workers. Cochrane Database Syst Rev. 2011;15:CD005958.

5. Martimo KP, Verbeek J, Karppinen J, et al. Manual material handling advice and assistive devices for preventing and treating back pain in workers. Cochrane Database Syst Rev 2007; 18:CD005958.

\section{Response: Safe Lifting}

\section{To the Editor:}

$\mathrm{L}$ ift-related musculoskeletal disorders among caregivers in long-term care facilities were the subject of our reports. Therefore, we focused our literature search on studies that spoke directly to this population. These studies examined the impact of safe lifting programs and powered mechanical lift use on caregiver injuries. Cohort studies of caregiver injury and cost outcomes found that a comprehensive safe lifting program in the context of adequate numbers of lifts reduced injuries and costs (see, eg, Refs. ${ }^{1-3}$ ). A cross-sectional study found that the provision of powered mechanical lifts reduced caregiver injuries and costs but training had equivocal impact. ${ }^{4}$

Given the specificities of our interest, our literature review did not include the excellent Cochrane review on back pain, ${ }^{5}$ authored by Verbeek and colleagues, because it included a broad range of industries and examined diverse training programs with a wide range of assistive devices available to workers. It also excluded studies that bore directly on our area of interest (see Refs. 1 to 4 ) if they did not meet the Cochrane review's criteria for inclusion (randomized controlled trials or cohort studies with contemporary controls).

Verbeek et $\mathrm{al}^{5}$ found specific training actions alone or with assistive devices to be ineffective in reducing back pain. We found that a comprehensive safe lifting program did reduce lift-related injuries. Although our results stand in contrast to the Cochrane review findings, these are consistent with the findings of other safe lift intervention studies referenced earlier.

Our differences may be due to the potentially material difference in the outcome variables - back pain versus something that results in a workers' compensation claim. It has been reported that over time lower back pain affects almost a third of the US population, that the cause of most pain due to lower back issues cannot be clearly identified, and that most "correct" on their own in a matter of a few weeks although they are likely to reoccur. ${ }^{6,7}$ Also, our outcome variables were limited to lift-related injuries. This increases our chances of finding an effect of efforts specifically targeted to reduce lift-related injuries.

Finally, our differences in findings may be because our predictor was a comprehensive measure of safe lifting, while the Cochran review included studies that measured different training actions. A multifactorial approach rather than a focus solely on training may be necessary to effect change. In our Safe Lift Index, we include not only measures of caregiver training but also assessment of the degree to which the facility considers safe lifting (ie, use of powered mechanical lifts) to be important and reinforces its use. Our Safe Lift Index was designed to assess the comprehensiveness of the safe lift policy. We think that the more comprehensive and the less piecemeal is the policy, the better its chance to succeed, at least in the specific setting of long-term care that we studied.
Patricia W. Gucer, PhD

Occupational Health Program, University of Maryland School of Medicine

Baltimore, $\mathrm{Md}$

Tanya Restrepo, MBA

National Council on Compensation Insurance, Inc

Boca Raton, Fla

Harry Shuford, PhD

National Council on Compensation Insurance, Inc

Boca Raton, Fla

Melissa McDiarmid, MD, MPH, DABT

Occupational Health Program, University of Maryland School of Medicine Baltimore, $\mathrm{Md}$

\section{REFERENCES}

1. Collins J, Wolf L, Bell J, Evanoff B. An evaluation of a "best practices" musculoskeletal injury prevention program in nursing homes. Inj Prev. 2004;10:206-211.

2. Evanoff B, Wolf L, Aton E, Canos J, Collins J. Reduction in injury rates in nursing personnel through introduction of mechanical lifts in the workplace. Am J Ind Med. 2003;44:451-457.

3. Brophy MO, Achimore L, Moore-Dawson J. Reducing incidence of low-back injuries reduces cost. AIHAJ. 2001;62:508-511.

4. Park RM, Bushnell PT, Bailer AJ, Collins JW, Stayner LT. Impact of publicly sponsored interventions on musculoskeletal injury claims in nursing homes. Am J Ind Med. 2009;52:683-697.

5. Verbeek JH, Martimo KP, Karppinen J, Kuijer PPFM, Viikari-Juntura E, Takela Takela P. Manual material handling advice and assistive devices for preventing and treating back pain in workers (review). Prepared and maintained by The Cochrane Collaboration and Published in The Cochrane Library. Available at: http://www.the cochraneo8brary.com. Accessed June 6, 2011.

6. Carey et al, NEJM 1995 and Wahlgren et al. Pain 1997 as summarized by Nina McIltree. Paper presented at Fifth Annual WC Customer Forum on "The Spine," Zurich Service Corp, March 25.

7. "Prescription Drugs: Abuse and Addiction," National Institute of Drug Abuse (NIDA) Research Report, October 2011.

\footnotetext{
The authors declare no conflicts of interest.

Copyright (C) 2013 by American College of Occupational and Environmental Medicine

DOI: 10.1097/JOM.0b013e3182a3bb5c
} 